\title{
Distance/Internet Astronomy Education
}

\author{
David H. McKinnon \\ Charles Sturt University, Bathurst, Australia \\ E-mail: DMckinnon@csu.edu.au
}

\section{Introduction}

This paper briefly reports two major programs being operated by Charles Sturt University, Bathurst: the Cosmology Distinction Course for gifted and talented senior high school students and the CSU Remote Telescope Project for upperelementary and lower secondary school students.

\section{Cosmology Distinction Course (CDC)}

The CDC was first offered in 1994 to students in New South Wales (NSW) who had completed one Higher School Certificate (HSC) course at the highest course level ahead of their age cohort and who were in the top 10 percent of the candidature. Numbers enrolling in the CDC are low (average of 20/year since 1994), and reflects the low number of schools in NSW who allow students to accelerate in their normal school programs. Nonetheless, a key factor in the success of the CDC has been the extensive use of Information and Communications Technologies (ICTs) through an integrated web site comprising a communication forum and a resource finder for the latest research in Cosmology.

\subsection{Methodology to evaluate the CDC}

A grounded theoretical analysis of the data collected from students use of the ICT system over four years gave rise to an Interactive Design Model (IDM). It comprises three key design elements, print-based study modules, residential schools and significant others, and a communication system for linking the students with the elements and with each other (McKinnon \& Nolan, 1999).

Course materials organize and sequence the objectives, content and assessment tasks into manageable units of study over the nine months of the course. Two residential schools bring the students together to: meet and interact with each other; engage in experiential learning at world-class observatories; and, learn from, and interact with, leading researchers. Significant others include the students peers, the course coordinator, course organizers, and research astronomers who provide students with support and guidance. The significant others interact with the students in varying capacities as social friends, critical friends, facilitators of learning, mentors, interpreters and discussants. The communication system mediates all student interactions with the three design elements of the Model. It provides them with the means to study not only the content of the course but also to access a wider range of information and ideas, and significant other individuals with whom to explore and discuss ideas. 


\section{Charles Sturt University Remote Telescope Project (CSURTP)}

The CSURTP is framed against the larger projects of Telescopes in Education, the Bradford Robotic Telescope and the Faulkes Project. The project takes elements from these and renders the technicalities of control at a level where elementary and junior secondary age students and their teachers can easily use the system. The software and hardware systems to drive the CSURTP are described elsewhere as are the educational materials written to support the project (e.g., McKinnon \& Geissinger 2002; McKinnon, Geissinger \& Danaia 2002; McKinnon \& Mainwaring 2000)

\subsection{Educational Package Evaluations}

Educational materials are supplied in printed Teachers' Guides and on CDRoms. The guides provide an extensive set of material covering a large number of topics. The elementary school materials are interdisciplinary. The high schools materials focus on science and technology. Elementary school materials engage the students for 4 hours/day, 4 days/week for 10 weeks. Secondary school materials engage students for six weeks of science periods (six per week). Two web sites point to resources available on the Internet. When schools come online, a technician is available to offer help.

In 2001-2003, students in grades 5-10 took part in evaluating: the materials; the user interface; and, the learning outcomes (alternative scientific conceptions) (Dunlop 2000; Osborne 1995).

\subsection{Method}

Quasi-experimental pre-test, post-test designs were used to evaluate the impact of the educational materials. Test results were subjected to ANOVA procedures with repeated measures on the occasion of testing. In addition, qualitative data were gathered from all participants to demonstrate how the educational programs were received and used.

\subsection{Results - Elementary School}

The specific test results are reported in detail in various publications (McKinnon \& Geissinger 2002; McKinnon, Geissinger \& Danaia 2002). Only the highlights of the findings are given here.

The quantitative results showed that classes who interacted with the educational materials demonstrated significant learning outcomes. Effect sizes ranged from 0.5 to 0.75 in students' general knowledge about astronomy, spatial knowledge of how the planets and Moon move, and on their ability to explain their answers.

There is, however, an interesting aside to the above statistical picture exemplified by one class and which should cause all educators some concern as well as astronomers making remote and robotic telescopes available to students. One class had previously covered a topic on the Earth in Space and had visited the library and conducted research using information and computer technologies (ICTs) to produce the posters that are a normal demonstration of learning in school. Their teacher did not want to cover the educational materials apart from the taking control and image processing sequences. On the pre-test, students 
knowledge and ability to explain phenomena was not significantly different from the other classes. They knew how to assemble attractive posters but knew little about astronomy despite the claim that they had already done that. The spatial knowledge post-test revealed that the scores of this class did not rise at all. On average, they achieved a score of 20 percent on both spatial knowledge scales. They knew little about phases of the Moon, day and night, the seasons, and what causes these phenomena.

One outcome clearly demonstrated by this research is that classes who concentrate mainly on the technical aspects show little change in their alternative conceptions of solar system phenomena. Students explorations of various phenomena, coupled with peer discussion and verbal reworking of concepts, enable them to discard some of their more naive ideas. Taking control of a sophisticated telescope is a great motivator that helps maintain their interest. The evidence supports the position that engaging with astronomy concepts leads to more insightful learning than does a concentration on mere technical details.

\subsection{Results - Secondary School}

Two cohorts of grade 9/10 students from the Netherlands and Canada evaluated the junior secondary science materials during 2003. Approximately 350 students supplied data which is yet to be analyzed. Extensive qualitative data illustrates that science teachers in both countries are highly impressed with the curriculum materials, the motivation of their students and the ease with which the system can be used.

A Canadian teacher ran the program with three grade 9 classes and also the school Astronomical Society. Members undertook a number of projects including mosaics of extended objects such as the Moon, M42 and omega Centauri, and multiple exposures of faint objects to practice stacking. Classes collaborated to take exposures of Uranus, Neptune and Pluto and traded their images to see how these planets could be identified by their movement against the stars. After a session with a grade 9 class containing at risk students he e-mailed:

"From an educational point of view... when at risk and beyond kids produce a report with enhanced images of their choice accompanied by a bit of research I know we have done something very significant over the past few months. This is priceless!!"

There is little doubt that taking control of a telescope over the Internet is a motivating experience for both elementary and secondary school students. The control aspect sustains their interest in the science over a considerable period of time. It is perhaps, this capacity of the control dimension to sustain interest that allows teachers the luxury to address the deeper scientific content and students alternative scientific conceptions as was demonstrated in the elementary school program.

\section{Discussion}

The key question to answer here is what does the Cosmology Distinction Course offer students that their schools cannot? Part of the answer is at least clear. The students get access to committed, intelligent, motivated, persistent and passionate researchers in astronomy and cosmology who are excellent communicators. 
A second key aspect of the course is the support that they get as they study the course and which is available through the ICTs. The completion rate is extremely high. In most years it is greater than 90 percent. Science delivered by distance methods has to be high touch (Naisbitt \& Aburdene 1990). The students are mentored during their candidature and feel a part of a community of learners.

The case for the CSU Remote Telescope Project is rather similar. The fact that the telescope is not a robotic device has many advantages (and disadvantages). One advantage is that it is high touch. Elementary teachers and secondary science teachers are, in the main, not adventurous. Both sets appear to need their hands held while they prepare to use the telescope, while their students use the telescope, and later in the debrief sessions as their students process the images.

\section{References}

Dunlop, J. 2000, "How children observe the universe", Publications of the Astronomical Society of Australia 17, 194-206

McKinnon, D. H., Geissinger, H. \& Danaia, L. 2002, "Helping them understand: Astronomy for Grades 5 and 6", Information Technology in Childhood Education Annual 2002, 1, 263-275

McKinnon, D.H. \& Mainwaring, A. 2000, "The Charles Sturt University Remote Telescope Project: Astronomy for Primary School Students", Publications of the Astronomical Society of Australia, 17, 2, 133-140

McKinnon, D.H. \& Nolan, C.J.P. 1999, "Distance education for the gifted and talented: An interactive design model", The Roeper Review, 21, 4, 320-325

McKinnon, D.H. \& Geissinger, H. 2002, "Helping them understand: Astronomy for Grades 5 and 6", Information Technology in Childhood Education Annual. 2002, 1, 263-275.

McKinnon, D.H. \& Geissinger, H. 2002, "Interactive Astronomy in Elementary Schools", Journal of International Forum of Educational Technology \& Society, 5, 1, pp $124-128$

Naisbitt, J. \& Aburdene, P. 1990, Megatrends 2000: Ten new directions for the 1990s, New York: Morrow

Osborne, J. 1995, "Common Ideas in Astronomy Questionnaire, Kings College: London 